\title{
$\widehat{A}$ Madridge \\ madridge Journal of Dermatology \& Research \\ Interconnecting Scientific World
}

Review Article

Open Access

\section{Contouring of Lower Face and Chin in Consideration of Facial Morphotypes and Shapes- Is it a More Accurate Approach?}

\author{
Yutskovskaya Yana Alexandrovna ${ }^{1 \star}$, Sergeeva Anna Daniilovna ${ }^{2}$, AI Kislitsyna $^{3}$ and Landau Marina ${ }^{4}$ \\ ${ }^{\prime}$ Dermatology, Pacific State Medical University, Vladivostok, Russia \\ 2Private practice, "Clinic of Prof. Yutskovskaya", Moscow, Russia \\ ${ }^{3}$ Moscow Scientific and Practical Center for Dermatovenereology and Cosmetology of Ministry of Public Health of Moscow, Moscow, Russia \\ ${ }^{4}$ Dermatology, Wolfson Medical Center. Holon, Israel
}

\section{Article Info}

\author{
*Corresponding author: \\ Yutskovskaya Yana Alexandrovna \\ Professor \\ Pacific State Medical University \\ Vladivostok \\ Russia \\ E-mail:yutsk@mail.ru
}

Received: October 16, 2017

Accepted: December 23, 2017

Published: December 29, 2017

Citation: Yutskovskaya YA, Sergeeva AD, Kislitsyna Al, Landau M. Contouring of Lower Face and Chin in Consideration of Facial Morphotypes and Shapes- Is it a More Accurate Approach. Madridge I Dermatol Res. 2017; 2(1): 26-31.

doi: $10.18689 / \mathrm{mjdr}-1000107$

Copyright: @ $\odot 2017$ The Author(s). This work is licensed under a Creative Commons Attribution 4.0 International License, which permits unrestricted use, distribution, and reproduction in any medium, provided the original work is properly cited.

Published by Madridge Publishers

\begin{abstract}
Different facial morphotypes have been described according to the soft tissue structure and characteristic aging patterns. Non-surgical correction of lower face is challenging in general, and has to be tailored according to the specific morphotype. In the current publication, we share our experience in treating lower face aging using injections. Our approach is based on the specific morphotypic features of each face.
\end{abstract}

Keywords: Morphotype; Dermal Filler; Botulinum Toxin; Lower Face; Chin.

\section{Introduction}

Facial aging is a universal process and occurs at all levels: skin, subcutaneous soft tissue and bony structures. Nevertheless, different people age differently. Therefore, when addressing facial aging, a personalized approach is required. Herein, we describe our approach to the lower face based among the rest, on the patient's morphotype.

\section{Facial Morphotypes}

The specific pattern of aging is dependent on genetic and environmental factors [1]. In addition, every ethnic group has its esthetically strong and weak points, that affect aging. For example, while Caucasian faces are generally narrower with greater vertical height and pronounced 3D projection, Asians tend to have a wider and flatter faces with shorter vertical height [2]. Furthermore, the concept of different facial morphotypes sometimes existing within the same ethnic group is widely accepted in some parts of the world [3]. Four principal morphotypes have been identified among Caucasian females: worn, wrinkly, deformed and muscular. Each one of them has specific characteristics.

The worn morphotype is the most common type, appearing in women with relative low body mass and oval or diamond-shaped facial shape (Fig 1a). The main features in aging of this morphotype are early loss of skin tonus with subsequent deepening of nasolabial fold, down turning of mouth corners and early appearance of tear trough deformity and labiomandibular (marionette) folds. Women presenting with worn morphotype usually complain on a tired appearance and can be successfully treated by injection therapy, mainly by fillers. 

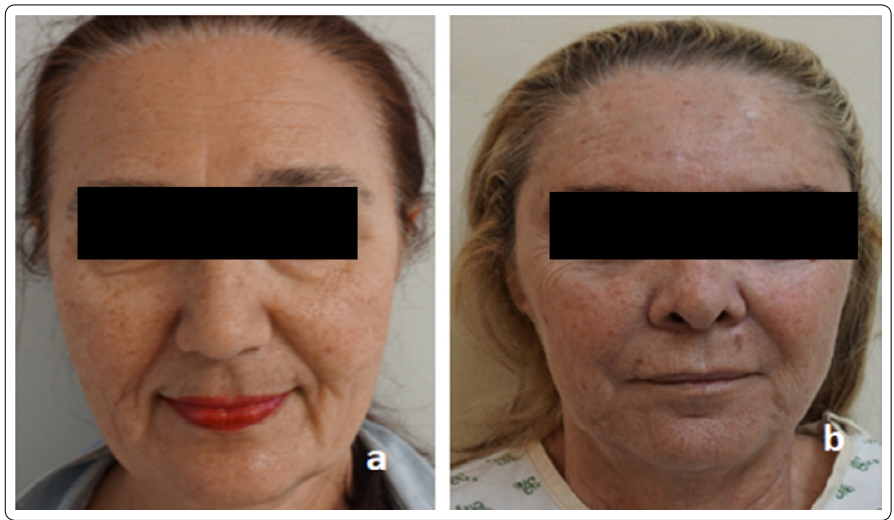

Wrinkly morphotype is characterized by multiple wrinkles in women with thin skin, extensive photodamage and poorly developed subdermal fat compartments (Fig. 1b). The clinical spectrum of wrinkly morphotype is addressed by correction of photodamage, resurfacing procedures, biorevitalization and skin boosting.

Deformed morphotype is characterized by a thicker skin and abundant subdermal fat compartments (Fig. 1c). Due to heaviness of the soft tissues, the main complain usually is sagging or "falling» of the face. These patients are candidates for surgical interventions.

Muscular morphotype presents with strong facial muscles and relatively under-developed fat compartments. (Fig. 1d) Aging is presented in this morphotype mainly by early appearance of the facial folds, mimetic wrinkles, and dyschromia. No skin wrinkles are seen otherwise. Well defined jaw line and facial oval, as well as neck skin quality are preserved into the older ages.
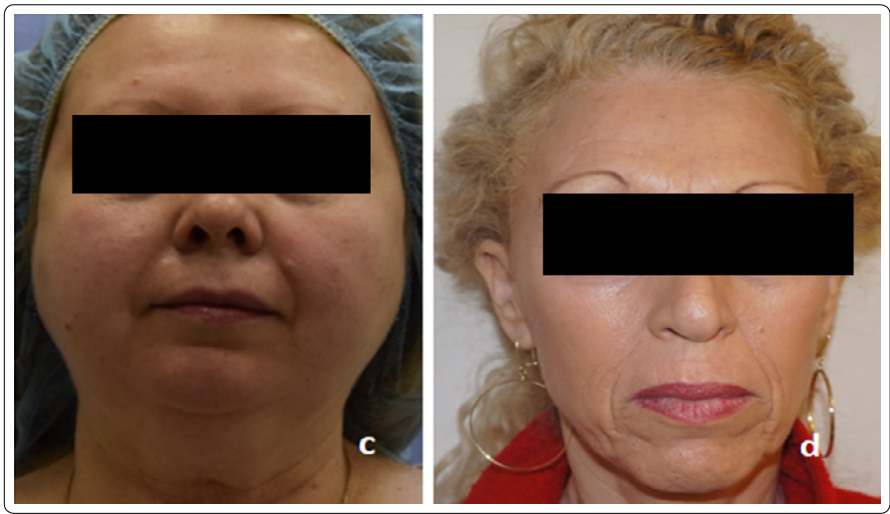

Figure 1. Four principal morphotypes have been identified among Caucasian females: a. worn, b. wrinkly, c. deformed and d. muscular.

\section{Facial Shape}

In the beauty industry, whether it is makeup, hair or even clothing being discussed, face shape plays a significant role [4]. The basic facial shapes include oval, long, square, round, heart and diamond shaped. The definition of the specific shape is based on the measurement of forehead, cheekbones and jaw width in relation to the facial length. In addition, specific features, such as sharp versus soft and round jaw line differentiate between square and round facial shape when all the other measurements are approximately similar. Pointed chin is typical for the heart shaped face. The ideal shape for women is considered to be the oval face, while for a man a square shape is preferred.
It is quite surprising that no scientific data there have been published on this widely accepted concept of the effect of facial shape on human attractiveness in general and its effect on a specific pattern of facial aging.

The almost exclusive mentioning of facial shape is available in evolutional psychology, which refers to square male jaws as a dimorphic trait, which conveys dominancy and therefore increases male attractiveness [5]. Greg Godman attempted to construct an optimal outline of the female face by assessing 21 beautiful women faces [6]. Based on the distance between the medial canthi of the eyes, with the center of the line drawn between them as a point of reference, he calculated the average distance from this point to other points on the line along the facial oval of attractive women. The average bizygomatic distance (horizontal parameter) was found to be 4.3 times the intercanthal distance (ICD) with vertical dimension that averaged 6.3 times the ICD. Aging affects facial oval, since the contour of the lower face becomes more square than oval, as clearly illustrated by a validated scale [7]. In faces presenting with less than optimal shapes to start with, this change is exhibited earlier in life. Therefore, basic facial shape affects the strategy chosen for rejuvenation therapy.

\section{Lower Face Aging}

A youthful jawline is characterized by a straight line from the chin to the mandibular angle. Later in life classic signs of lower face aging appear. They result from a complex phenomenon, involving skin, fatty tissue, retaining ligaments and the bones. Facial shape continues changing throughout the entire life span due to morphological differentiation of the facial skeleton [8]. The characteristic changes in the aging facial skeleton include posterior displacement of the maxilla and shrinking of the mandible. Contour changes occur because of the volume losses and repositioning of the fat compartments, In addition, the borders between the fat compartments become visible [9]. All this gives off the appearance of increased soft tissue laxity, loss of the definition of the jawline, prominent marionette lines, and heavy jowls. In addition, increased platysmal resting tone is implicated in the muscular aging of the jaw line [10]. Genetically under developed or recessed chin contribute to early loss of definition of the jaw line, as the face lacks one of the most important soft tissue "stretchers" of this zone (Fig. 2).

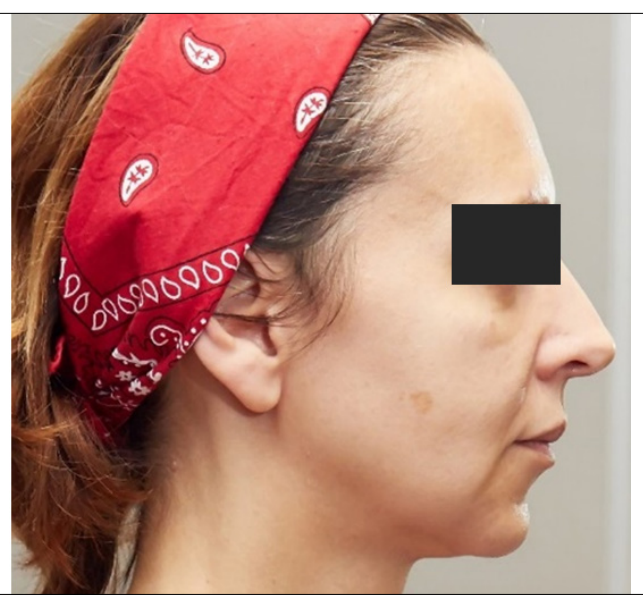

Figure 2. Genetically recessed chin contributes to early appearance of marionette folds and loss of definition of the jaw line. 


\section{Patient Selection}

Improvement of lower face contour is required by both females and males, of younger and older ages. A large European consumer survey has shown that the jaw line is a preferred feature to change for one-third of women aged 46-64 years [11]. Jaw line contouring is an important procedure in men, where replacing volume into the mandibular angle can create the strong posterior jaw line contour highlighting the masculinity.

In younger patients without sagging of the tissues, lower face enhancement can create more attractive facial shape. Keeping in mind that oval is a preferred form in female faces, reshaping of congenital square or round face can be performed. Augmentation of a recessed chin beautifies female face, masculinizes male's and contribute to facial harmony especially in Asian faces [2,5].

In women presenting worn and deformed morphotypes, lower face aging becomes evident from relatively young age, and they are good candidates for minimally invasive procedures addressing lower face issues.

\section{Techniques}

\section{Chin Augmentation}

Augmentation of the chin can be performed with injectable fillers, autologous fat, placement of an alloplast implant, or with a bony osteotomy. Surgical augmentation of the chin has been the gold standard of therapy. Recent development of injectable filler with more prominent lifting capacity has changed the way many practitioners alter chin shape and size [12]. Soft tissues of the chin are tight and adherent to the bone. Products with high lifting capacity (high $\mathrm{G}$ prime), such as Calcium hydroxyapatite and selective Hyaluronic acid (HA) based fillers are employed for chin augmentation. The product is delivered under the mentalis muscle on the periosteum in three boluses injected using a sharp needle (Fig. 3).

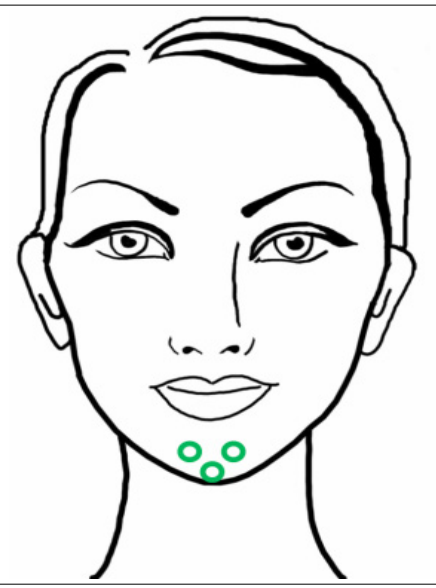

Figure 3. A scheme for chin augmentation using deep boluses of the product

Pre-injection aspiration is advisable [13]. Symmetry of the both sides of the chin should be assessed before the injection. If asymmetrical, bigger bolus is injected to the smaller side. The amount of the productis usually $1-1.5 \mathrm{ml}$. The "pocket» under mentalis is of a limited size. Bigger amounts of the filler will spread peripherally. The treatment can be repeated in 4-6 weeks. If the target of the treatment is chin elongation, pinching the chin between finger 1 and 2 of a non-dominant hand, «directs» the product to the right location (Fig. 4).

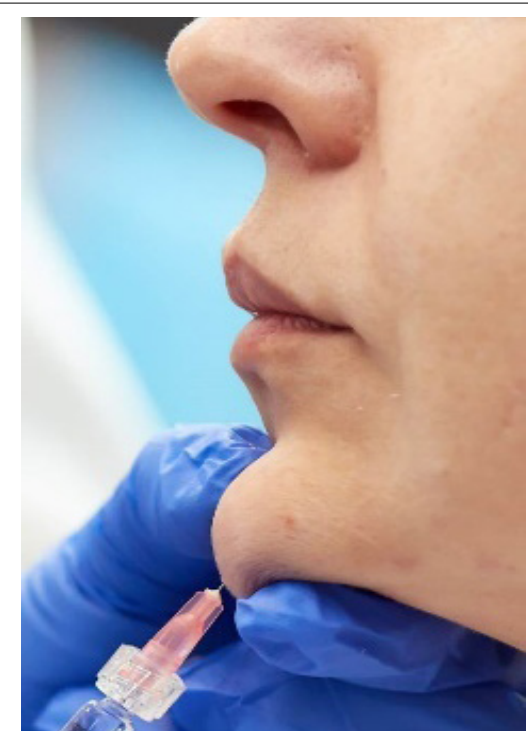

Figure 4. Pinching of the soft tissues to shape the chin.

The results of the procedure are immediately visible and appreciated (Fig. 5).

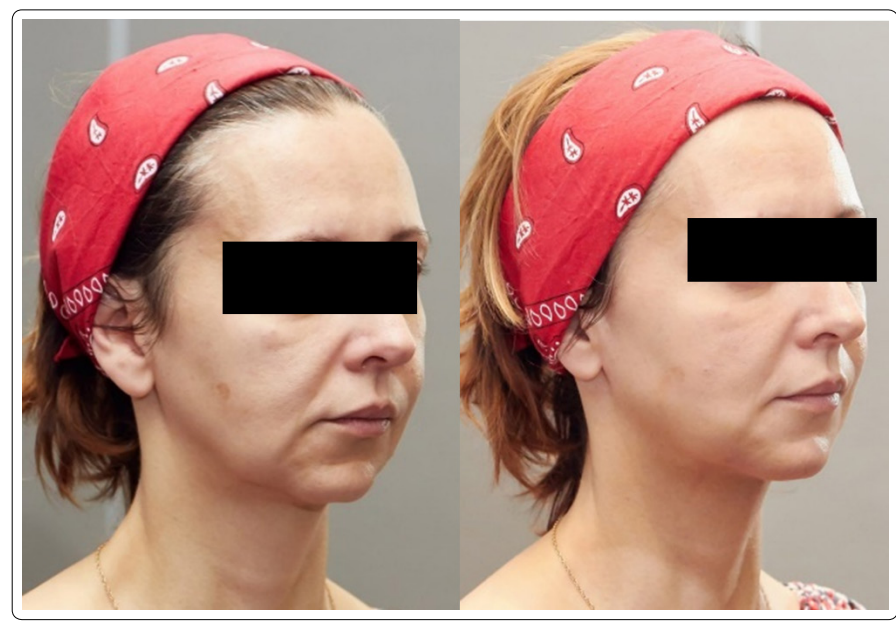

Figure 5. Patient before and after chin augmentation

For anterior projection of the chin Calcium hydroxyapatite diluted in ratio of 1:1 with normal saline or $\mathrm{HA}$ based filler is injected from the chin apex cephalically. The product is delivered through $25 \mathrm{G}$ cannula using subdermal fanning technique (Fig. 6).The overall amount of the product (before dilution) needed is $0.8-1.5 \mathrm{ml}$.

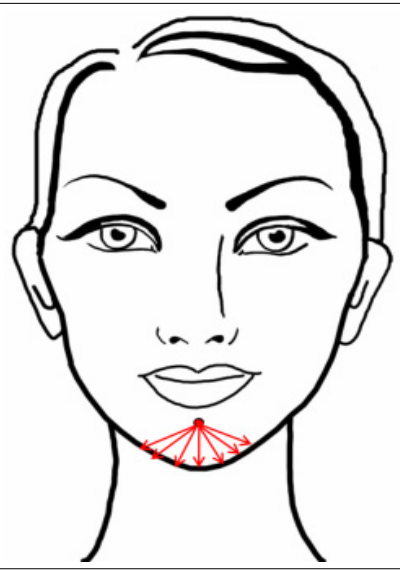

Figure 6. A Scheme for Subdermal Chin Enhancement 


\section{Botulinum Toxin Chin Injection}

The effect of Botulinum toxin on the chin shape cannot be overestimated. "Orange peel" skin over the chin, points on over-contraction of the mentalis muscle and should be addressed. Relaxation of a contacted chin is achieved by injecting 4 to 8 units of onabotulinumtoxin $A$ or incobotulinumtoxin $A$, or 10-20 units of abobotulinumtoxin $A$ at the midline approximately $0.5 \mathrm{~cm}$ above the most inferior point of the chin or devided to two lateral sites parallel to the midline. (Fig.7).

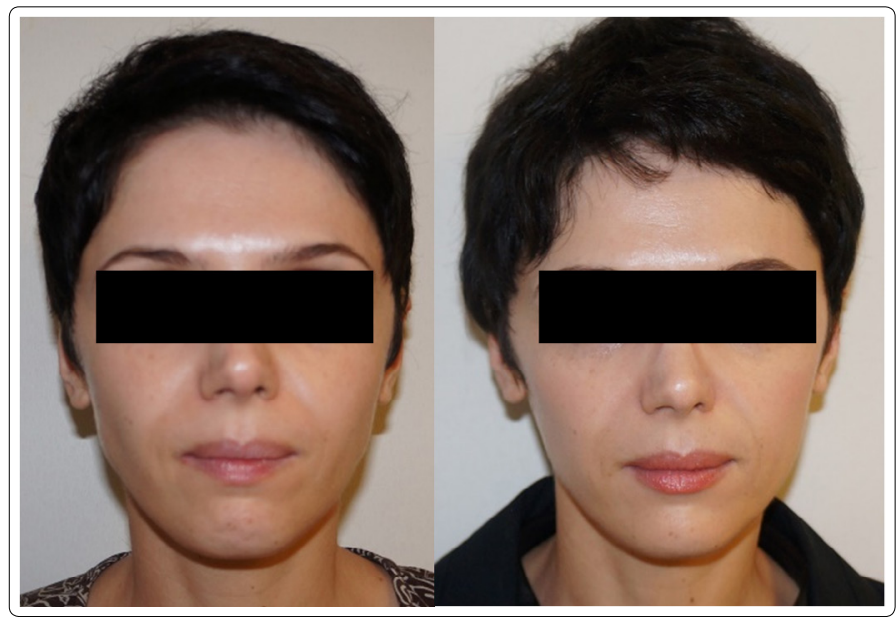

Figure 7. A patient before and after BoNt-A injection to chin

If performed two weeks before the chin augmentation procedure, relaxation of mentalis creates a bigger "pocket" under the relaxed muscle to allow more focused delivery of a filler.

\section{Marionette lines (Labiomandibular fold)}

Marionette lines give the face a sad or hard appearance. People often consider labiomandibular folds to be the most bothersome feature of their faces. Nevertheless, it is challenging to attain consistently good results when treating these lines non-surgically [14]. Anatomically this fold lies between the labiomandibular fat compartment and the prejowl fat. The medial edge of the depressor angulioris muscle follows the course of this crease [9]. Treatment of marionette lines can be performed by subcutaneous injection using a linear threading retrograde technique. Most of the product volume is delivered to the top third of the while staying medial to the marionette line $[13,14]$.

Our clinical approach to the marionette folds changes according to their severity, according to the validated scale [15]. For grade 1 marionette folds (shallow but visible fold with slight indentation) HA based filler or Calcium hydroxyapatite diluted with normal saline in ratio of $1: 1$ is delivered subdermally through $25 \mathrm{G}$ cannula. The entrance holes for the cannula are in both sides of the mandible above the mental foramina. (Fig.8, Fig 9a and 9b).

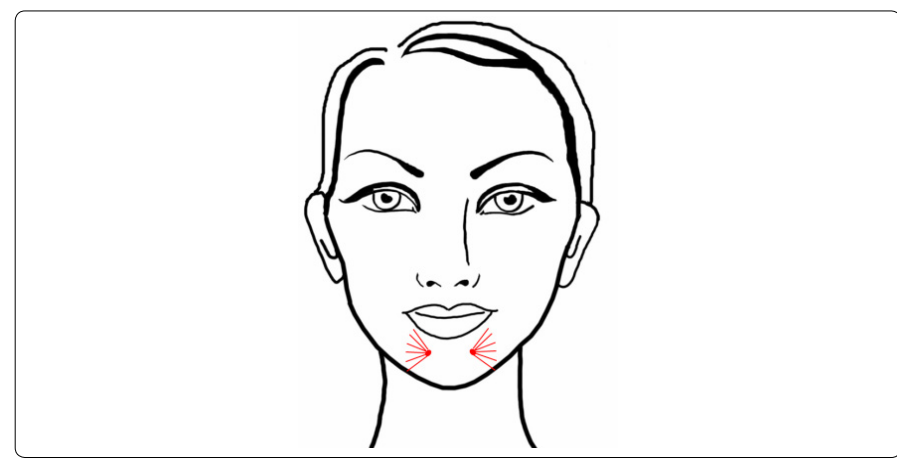

Figure 8. A scheme to treat grade 1 marionette folds with cannula

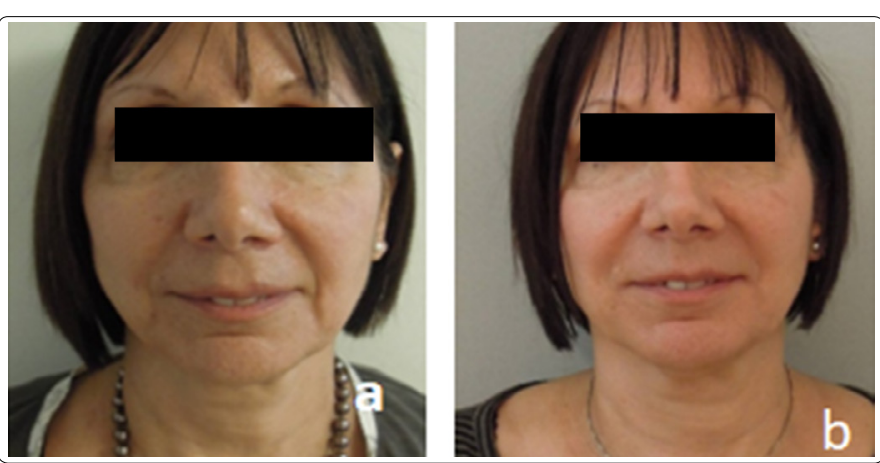

Figure 9. Mild marionette folds: a. before b. after the injection

Grade 2 to 4 marionette folds are usually associated with prominent jowls. In such cases pilot hole for the cannula is performed above the lower border of the mandibular bone 1 $\mathrm{cm}$ laterally to the intersection of marionette lines with the mandible. High G prime HA or diluted Calcium hydroxyapatite is fanned through the cannula medially to the fold to avoid overloading of the jowls (Fig. 10, Fig 11a and 11b).

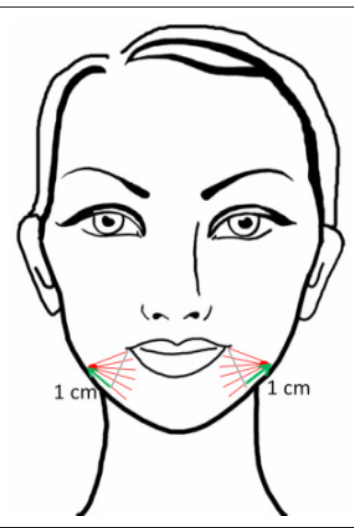

Figure 10. A scheme to treat grade 2 to 4 marionette folds.
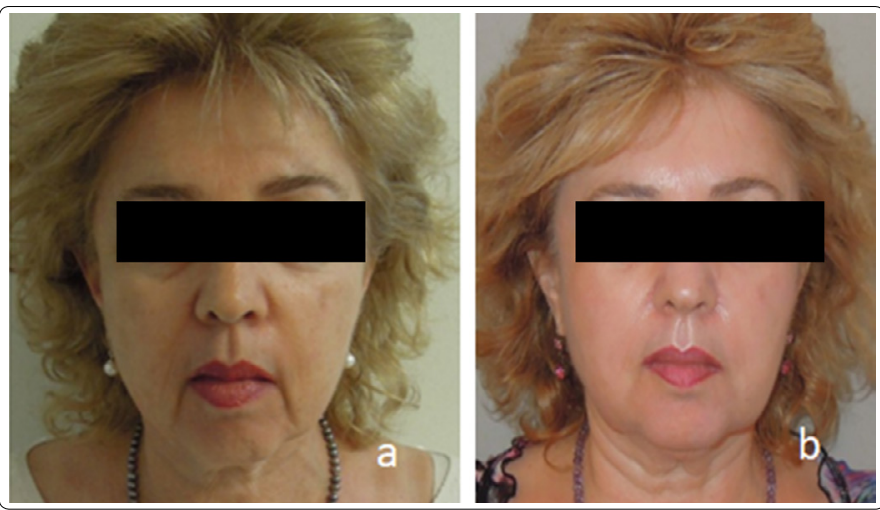

Figure 11. Moderate marionette folds: $a$. before $b$. after the injection 
Patients with triangular or heart shape faces, are in need for both chin augmentation and marionette folds correction. In these cases, high $\mathrm{G}$ prime HA or diluted Calcium hydroxyapatite is delivered through a cannula by alternative approach. The pilot hole is performed above the lower border of maxillary bone $1 \mathrm{~cm}$ lateral to the mid-pupillary line and the product is delivered to marionette folds and both sides of the chin. Attention should be payed to stay within the fold and avoid overloading of the jowls (Fig. 12).

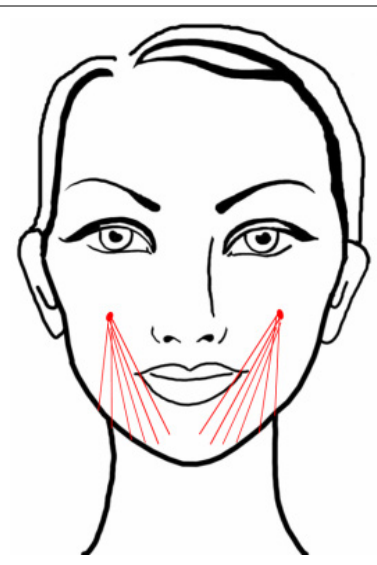

Figure 12. A scheme to treat a patient with triangular or heart shape faces to augment the chin and correct marionette lines.

\section{Jawline and Jowls}

A youthful jawline is characterized by a straight line from the chin to the mandibular angle. Later in life, it is interfered with the classic signs of lower-face aging, which include jowling and appearance of pre-jowl sulcus. The contour of the lower face becomes more square than oval, as clearly illustrated by a validated scale [7]. Pre-jowl sulcus is the triangular area from the mental foramen to the mid-lateral zone of the mandible. Jowls are located immediately after the sulcus and present as focused hanging zone of the soft tissue along the mandibular line.

Patients with heart or diamond shaped faces present with pre-jowl sulcus earlier in life, due to the inherent insufficient support of bony tissues along the anterior mandible. Grade 1 and 2 jowling, according to the validated scale of lower face aging, is treated by a high $\mathrm{G}$ prime HA or undiluted Calcium hydroxyapatite injected in deep boluses $[13,14]$. The needle is positioned at the mandibular line in the pre-jowl area. Preinjection aspiration is advised. Slow perpendicular injection is performed with few boluses of the filler delivered deeply on the periosteum of the mandible. Special attention is made to the area just below the mandible as there is often a significant depression. Fingers of a non-dominant hand block the possibility of displacement of the filler over the mandibular ligament (Fig. 13).

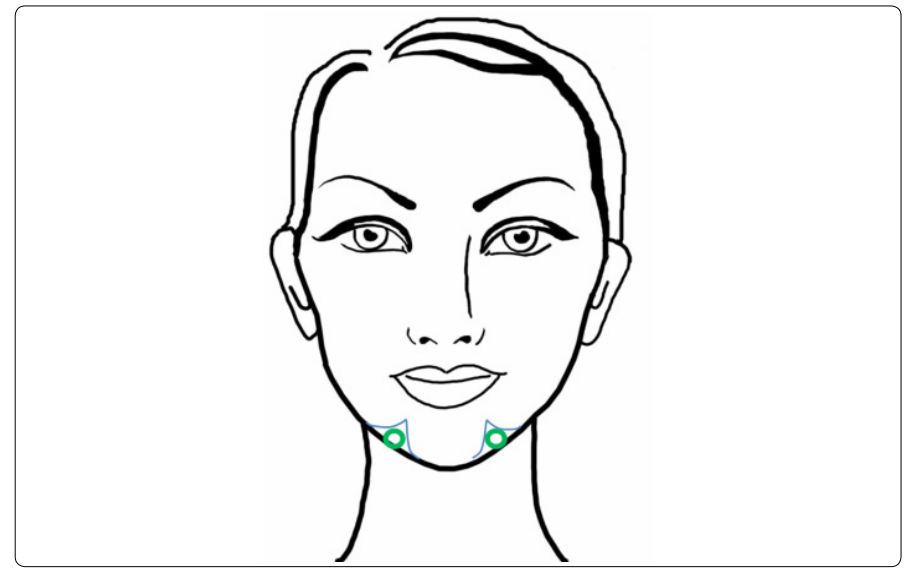

Figure 13. A scheme to correct pre-jawl sulcus grade 1

In more severe cases (grade 3 and 4 ) of jawline aging, post jowl concavity, mandibular angle, and sometimes zygoma have to be addressed for lifting effect. For post jowl concavity correction, subdermal injection of diluted Calcium hydroxyapatite is performed through cannula with a pilot hole located immediately lateral to the sulcus. If the injector prefers to use sharp needle, we suggest to pinch the skin to remain in the immediate subdermal plane to avoid facial artery. (Fig.14). Mandibular angles can be addressed similarly. If sufficient effect is not achieved, we recommend to consider injectiong both posterior cheek and malar area, as suggeted by others [16].

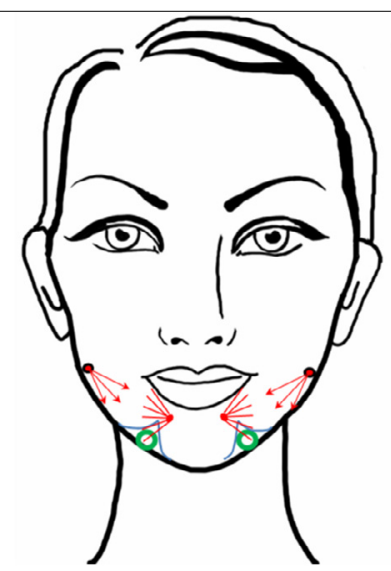

Figure 14. A scheme to correct severe marionette lines.

\section{Botulinum Toxin for Jawline Redefinition}

Traditionally used to relax platysmal bands, botulinum toxin can tighten the neck and induce some jawline recontouring [17]. Injection of botulinum toxin along the mandibular line and into the upper portion of the posterior platysmal bands, creates a visible release of the platysma muscle's downward pulling and jawline recontouring [18]. To treat the lower face as a single unit, anterior and posterior jawline injections must be combined. According to the recent study, by injecting the mentalis muscle intramuscularly, followed by serial superficialBoNT-A injections along the mandible and below it, up to the mandibular border, facial contour can be enhanced, particularly during lower facial muscular contraction (Fig.15) [19]. In addition, the skin becomes more tightly opposed to the bone structure of the mandible. The total required dose per side is 14-18 units of onabotulinumtoxin A or incobotilunimtoxin A or 35-45 units of abobotulinumtoxin A. 


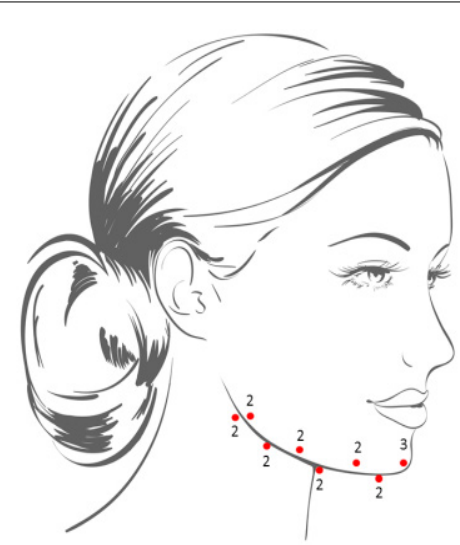

Figure 15. A scheme and doses for jaw line recontouring with BoNT-A.

\section{Submental Zone and Cervicomental Angle}

Well defined and open angle between the chin and the neck contributes to the youthful appearance of the lower face and the neck. Ideally, cervicomental angle should be between $105^{\circ}$ and $120^{\circ}$ [20]. Minimal changes of the submental area can be addressed with dermal fillers, if the changes are related to the loss of skin elasticity and not submental fat accumulation. In such a case, we recommend on reinforcement and stimulation of the skin in the submental zone by using diluted 1:1 Calcium hydroxyapatite [21]. The amount of the product required is $1.5 \mathrm{ml}$ before the dilution. The injection is performed by 25G $50 \mathrm{~mm}$ cannula through 3 entrance holes: central submental point and two points below both submandibular joints (Fig. 16).

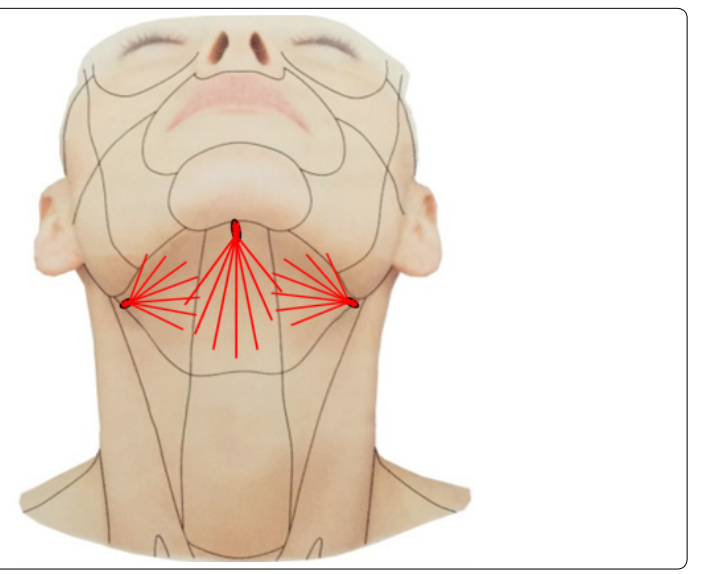

Figure 16. A scheme for submental reinforcement.

Other minimally invasive therapy to address lower face aging. In the last years a plethora of methods targeting to non-surgically rejuvenate lower face has hit the markets. It includes high intensity focused ultrasound, invasive radiofrequency, specific lasers, threads, cryolipolysis, etc. The discussion of these technologies is above the scope of the current publication.

\section{References}

1. Guyuron $B$, Rowe DJ, Weinfeld $A B$, Eshraghi $Y$, Fathi A, lamphongsai $S$. Factors contributing to the facial aging of identical twins. Plast Reconstr Surg. 2009; 123(4): 1321-1331. doi: 10.1097/PRS.0b013e31819c4d42

2. Rho NK, Chang YY, Chao YY, et al. Consensus Recommendations for Optimal Augmentation of the Asian Face with Hyaluronic Acid and Calcium Hydroxylapatite Fillers. Plast Reconstr Surg. 2015; 136(5): 940-956. doi: 10.1097/PRS.0000000000001706

3. Kolgunenko II. Fundamentals of Gerontocosmetology. Moscow: Medicine; 1974. $224 \mathrm{p}$.

4. Shome D. The Best Face Shape for you - How to get it? The Esthetic Clinic. 2015.

5. Little AC, Hancock PJ. The role of masculinity and distinctiveness in judgments of human male facial attractiveness. Br J Psychol. 2002; 93(4): 451-464.

6. Goodman GJ. The oval female facial shape-A study in beauty. Dermatol Surg. 2015; 41(12):1375-1383. doi: 10.1097/DSS.0000000000000571

7. Narins RS, Carruthers J, Flynn TC, et al. Validated assessment scales for the lower face. Dermatol Surg. 2012; 38(2): 333-342. doi: 10.1111/j.1524-4725.2011.02247.x

8. Shaw RB, Katzel EB, Koltz PF, Kahn DM, Girotto JA, Langstein HN. Aging of the mandible and its aesthetic implications. Plast Reconstr Surg. 2010; 125(1): 332-342. doi: 10.1097/PRS.0b013e3181c2a685

9. Gieroff $M$, Stihring $C$, Buder $T$, Wiltfang J. The subcutaneous fat compartments in relation to aesthetically important facial folds and rhytides. J Plast Reconstr Aesthet Surg. 2012; 65(10):1292-1297. doi: 10.1016/j.bjps.2012.04.047

10. de Almeida ART, Romiti A, Carruthers JDA. The facial platysma and its underappreciated role in lower face dynamics and contour. Dermatol Surg. 2017; 43(8): 1042-1049. doi: 10.1097/DSS.0000000000001135

11. Baspeyras M, Dallara JM, Cartier H, Charavel MH, Dumas L. Restoring jawline contour with calcium hydroxylapatite: A prospective, observational study. J Cosmet Dermatol. 2017;16(3): 342-347. doi: 10.1111/jocd.12335

12. Sykes JM, Fitzgerald R. Choosing the best procedure to augment the chin: Is anything better than an implant? Facial Plast Surg. 2016; 32(5): 507-512. doi: 10.1055/s-0036-1592162

13. deMaio M, Wu WTL, Goodman GJ, Monheit G. Facial assessment and injection guide for Botulinum toxin and injectable hyaluronic acid fillers: Focus on the lower face. Plast Reconstr Surg. 2017; 140(3): 393-404. doi: 10.1097/PRS.00000000000003646

14. Braz A, Humphrey $S$, Weinkle $S$, et al. Lower face: Clinical anatomy and regional approaches with injectable fillers. Plast Reconstr Surg. 2015; 136(5): 235-257. doi: 10.1097/PRS.0000000000001836

15. Carruthers A, Carruthers J, Hardas B, Kaur M, Jones D, Rzany B, et al. A validated grading scale for marionette lines. Dermatol Surg. 2008; 34(2): 167-172. doi: 10.1111/j.1524-4725.2008.34366.x

16. Dallara J-M, Baypeyras M, Bui M, Cartier H, Charavel M-H, Dumas L. Calcium hydroxylapatite for jawline rejuvenation: consensus recommendations. $J$ Cosmet Dermatol. 2013; 13(1): 3-14. doi: 10.1111/jocd.12074

17. Brandt FS, Bellman B. Cosmetic use of botulinum A exotoxin for the aging neck. Dermatol Surg. 1998; 24(11): 1232-1234.

18. Levy PM. The "Nefertiti lift": a new technique for specific re-contouring of the jawline. J Cosmet Laser Ther. 2007; 9(4): 249-252. doi: 10.1080/14764170701545657

19. de Almeida ART, Romiti A, Carruthers JDA. The facial platysma and its underappreciated role in lower face dynamics and contour. Dermatol Surg. 2017; 43(8): 1042-1049. doi: 10.1097/DSS.0000000000001135

20. Ellenbogen $R$, Karlin JV. Visual criteria for success in restoring the youthful neck. PlastReconstr Surg. 1980; 66(6): 826-837.

21. Loghem JV, Yutskovskaya YA, Philip Werschler W. Calcium hydroxylapatite: over a decade of clinical experience. J Clin Aesthet Dermatol. 2015; 8(1): 38-49. 